BOOK REVIEWS-(Continued from page 532)

\section{THE ELECTRICAL ACTIVITY OF THE NERVOUS SYSTEM}

By Mary A. B. Brazier, B.Sc., Ph.D.(Lond.). Pp. $x+220$ with 96 illustrations. London: Isaac Pitman. r95I. 25s.

In this book the main developments in this field of neurophysiology are concisely presented. Anyone with an elementary knowledge of the subject will be able to understand it readily in spite of a slightly difficult style.

The bibliography is very useful. The standard of publishing is excellent.

\section{THE VERSATILE VICTORIAN}

\section{The Life of Sir Henry Thompson, Bt.}

By Zachary Cope, M.D. Pp. xi +179 , with ro illustrations. London: Harvey and Blythe. I95 I. 12s. 6d.

This is an extraordinarily interesting book. It is firstly the biography of an outstanding personality, but it also gives fascinating and intimate glimpses of the Victorian era and of many of its leading figures.

Henry Thompson's early wishes to study medicine were opposed by his father who insisted on his entering the family business. Only at the age of 26 , therefore, was he able to take up his life's work, becoming a medical student at University College Hospital. Here he came under the influence of Liston, some idea of which can be drawn from the fact that after Liston's sudden death more than 600 medical men and students attended his funeral at Highgate cemetery. As a house surgeon, one of Thompson's first dressers was Lister; it appears that it was he who suggested that Lister should go to Edinburgh to work with Syme. $\mathrm{He}$ gives a detailed account of medical student life of the time, including his enrolment as a special constable during the Chartist riots reminiscent of similar troubles in more recent times.

After qualification and a brief adventure in general practice, he set himself steadfastly to master the surgery of the lower urinary tract, gaining the Jacksonian prize for his essay on 'Stricture.' $\mathrm{He}$ thereafter went to Paris where he studied lithotrity as practised by Civiale-a subject in which he subsequently outstripped his teacher. The story of how he successfully crushed and removed a stone from King Leopold of the Belgians after Civiale and Langenbeck (of Berlin) had in turn failed, bears testimony to his prowess. His charming letter too his teacher, Civiale, after his triumph, which re-? sulted in a life-long friendship, is an object lesson. For more than 30 years he remained at the top of the surgical tree in his own speciality, being con-? sulted by patients in all walks of life from the royale family downwards, his fees being commensurate. In later years he presented to the Royal College of Surgeons his collection, unfortunately destroyed byฉ the bombing of the College in 1942, of 1,000 bladder stones which he had crushed and removed.

Outside the profession his interests were be- $\vec{\circ}$ wilderingly wide. In art, in music, in writing, he $\vec{\omega}$ was more than talented (he had 12 oil paintings hung by the Royal Academy over a period of 368 years, whilst his two novels were both successful). His collection of Nankin porcelain was world-i known, whilst his poultry farm was a model to. farmers. In gastronomy he was an epicure, and an invitation to his dinner parties (the famous 'oc-? taves ') meant that 'one had arrived.'

In brief, he achieved success in professional, $\stackrel{+}{\circ}$ artistic and social circles, being 'the favourite of women, of princes and of fortune.'

The author is to be heartily congratulated on his? lucid style, leaving much to his subject's own wordso and entirely avoiding the burdensome detail so apt $\mathbb{\mathbb { }}$ to appear in biography of that time. The production $\overrightarrow{0}$ is good and the illustrations excellent.

Both as a story and for the light it throws on the life and personalities of last century, this book tso strongly commended to all readers.

\section{GOOD HEALTH WITH DIABETES}

By IAN MURRAY, M.D., F.R.F.P.S.G., F.R.C.P.E., and Margaret B. MuIR, S.R.N. 2nd Edition. Pp. iv + 44. Edinburgh: E. \& S. Livingstone I 95 I. 2 s.

This handbook for patients admirably fulfils the first essential of such a work, for it is written in simple, clear and concise English. The reasons are given for the necessity of dietary control, and a series of varied menus is followed by instructions $₹$ on taking insulin and testing urine, and by an 0 account of various diabetic emergencies. Since further editions of this book will undoubtedly be $\frac{}{2}$ called for, it is suggested that its practical value in enabling the diabetic to live a near-normal life N would be even further increased by including ' equivalent' values for beer and jam and by giving specimen menus for packed dinners. 